\title{
BRINCAR COM A LINGUAGEM: EDUCAÇÃO INFANTIL "RIMA" COM ALFABETIZAÇÃO?
}

\author{
JUGAR CON EL LENGUAJE: EDUCACIÓN INFANTIL “RIMA” CON \\ ALFABETIZACIÓN?
}

\section{PLAY WITH LANGUAGE: EARLY CHILDHOOD EDUCATION "RHYMES" WITH LITERACY?}

\author{
Liane Castro de ARAUJO ${ }^{1}$
}

RESUMO: O contexto atual de ampliação do sistema educacional para o segmento da Educação Infantil e de estabelecimento de metas de alfabetização até os 8 anos de idade justifica discutirmos sobre o papel que teria a Educação Infantil na alfabetização e no letramento. Ressalta-se a importância de situações significativas de leitura e escrita que garantam, na escola, a participação das crianças pequenas em práticas sociodiscursivas e, ao mesmo tempo, assegurem os seus modos próprios de aprender, que envolvem as interações e o brincar como princípios e como eixos do trabalho pedagógico. Reconhecendo o papel da Educação Infantil no letramento das crianças pequenas e enfatizando as práticas de leitura e escrita como interlocução, o presente ensaio pretende contribuir com a discussão sobre o papel desse segmento no processo específico de alfabetização, a partir de situações significativas de reflexão sobre a língua, especialmente sobre sua dimensão sonora, em contextos lúdicos e/ou letrados, envolvendo brincadeiras com a linguagem. Destacam-se aí as brincadeiras com os textos da tradição oral, presentes na escola como cultura lúdica, mas igualmente privilegiados para brincar com as sonoridades da língua e seus ajustes em relação à escrita, favorecendo o processo de apropriação da notação alfabética.

PALAVRAS-CHAVE: Educação infantil. Alfabetização. Letramento. Linguagem.

RESUMEN: El contexto actual de ampliación del sistema educacional para el segmento de la Educación Infantil y del establecimiento de metas de alfabetización hasta los 8 años de edad justifica la discusión sobre el papel que tendría la Educación Infantil en la alfabetización y en el aprendizaje de lectoescritura ("Letramento"). Se resalta la importancia de situaciones significativa de lectura y escritura que garanticen, en la escuela, la participación de los niños pequeños en prácticas sociodiscursivas y, a la vez, aseguren sus propios modos de aprender, que comprenden las interacciones y el jugar como principios y como eje del trabajo pedagógico. Reconociendo el papel de la Educación Infantil en el aprendizaje de lectoescritura ("Letramento") de los niños pequeños y enfatizando las prácticas de lectura y de escritura como interlocución, el presente artículo pretende contribuir con la discusión sobre el papel de ese segmento en el proceso específico de alfabetización, a partir de situaciones significativas de reflexión sobre la lengua, especialmente sobre su dimensión sonora, en contextos lúdicos y/o letrados, abarcando juego educativos con el lenguaje. Se destacan los juegos con los textos de tradición oral, presente en la escuela como cultura lúdica, pero igualmente privilegiados para jugar con las sonoridades de la lengua y sus ajustes respecto a la escritura, lo que favorece el proceso de apropiación de la representación escrita alfabética.

1 Doutora em Educação e Professora Adjunta - Faculdade de Educação, UFBA. Universidade Federal da Bahia, Salvador, Brasil. Email: lica@ufba.br 
PALABRAS CLAVE: Educación infantil. Alfabetización. Aprendizaje de lectoescritura ("letramento"). Lenguaje.

ABSTRACT: The current context of expanding the educational system for the segment of early childhood education and establishment of literacy goals to 8 years of age justifies discuss the role that would have early childhood education in literacy. We emphasize the importance of significant situations of reading and writing to ensure, at school, participation of young children in sociodiscursive practices and, at the same time, ensure their authentic ways of learning, involving interactions and play as principles and as axes of pedagogical work. Recognizing the role of early childhood education in literacy of young children and emphasizing reading and writing practices as dialogue, this paper aims to contribute to the discussion on the role of this segment in the specific process of literacy, from significant situations of reflection on the language, especially about their sound dimension, in entertainment and / or literate contexts involving jokes with language. Among these, we point out children's play with texts of oral tradition, present in school as playful culture, but also privileged to play with the sounds of the language and its adjustments in relation to writing, favoring the process of appropriation of alphabetical notation.

KEYWORDS: Early childhood education. Literacy. Language.

\section{Introdução}

A discussão sobre o papel da Educação Infantil nos processos de letramento e de alfabetização das crianças configura-se, atualmente, como uma questão fundamental, especialmente a partir da entrada recente desse segmento para o sistema de ensino, de seu caminho rumo à universalização e da ampliação do Ensino Fundamental para nove anos (BRASIL, 2009) - que tem repercussão, como ressalta Kleiman (2009), em todo o sistema educacional, inclusive na Educação Infantil. Soma-se, a esse aspecto, a meta governamental de alfabetização até os 8 anos de idade (BRASIL, 2014), que reforça, por um lado, a preocupação com as práticas da Educação Infantil e, por outro, a necessidade de que esse segmento assuma sua responsabilidade em oferecer um amplo convívio das crianças com práticas letradas, especialmente em relação àquelas que não têm oportunidades tão favoráveis de letramento fora da instituição escolar.

A polêmica em torno do papel da Educação Infantil no processo de alfabetização configura-se, muitas vezes, como uma polarização que opõe a educação das crianças pequenas, tomada como uma etapa importante em si mesma, com sua especificidade, e a 
ideia dessa etapa como preparação para o Ensino Fundamental. Mas será que a questão precisa ser colocada nesses termos? O que podemos pensar, fora dessa polarização, sobre as contribuições da Educação Infantil para o processo de alfabetização? Deve-se alfabetizar na Educação Infantil? A Educação Infantil deve preparar para a alfabetização?

A pergunta quanto a se devemos ou não alfabetizar na Educação Infantil é uma pergunta mal formulada, pois, como aponta Bresciane (2004), uma resposta positiva poderia implicar no adiantamento de práticas do $1^{\circ}$ ano, inclusive práticas mecânicas, e uma resposta negativa equivaleria a deixar toda a responsabilidade em relação à aprendizagem da leitura e escrita exclusivamente para o ciclo de alfabetização. Por outro lado, é preciso discutir, igualmente, o que seria "preparar” para a alfabetização, já que esse termo carrega conotações diversas, como as ideias, já combatidas no campo da educação pré-escolar, de pré-requisitos para a leitura e a escrita e da prontidão para a alfabetização.

O papel da Educação Infantil no letramento e alfabetização das crianças precisa ser debatido e compreendido, tanto em favor das práticas de leitura e escrita no próprio segmento da Educação Infantil, quanto em favor das práticas alfabetizadoras no ciclo da alfabetização. Partindo, inicialmente, do reconhecimento do papel da Educação Infantil no letramento - ou seja, na dimensão sociodiscursiva da aprendizagem da leitura e da escrita - o presente artigo discute sobre o lugar da brincadeira com a linguagem, especialmente em sua dimensão sonora, como uma prática lúdica e significativa na Educação Infantil, que contribui para o processo específico de apropriação da escrita alfabética, junto com as situações de reflexão em que a notação escrita se faz presente.

\section{Ler e escrever na Educação Infantil}

“A interação verbal constitui a realidade fundamental da língua". (BAKHTIN; VOLOCHINOV, 1981, p.123).

Do ponto de vista da Educação Infantil, ao mesmo tempo em que as crianças pequenas são inseridas na escola e que são reconhecidas como sujeitos de direitos e de cultura, seja por vários campos de conhecimento (SARMENTO, 2003; COHN, 2005), seja pelas novas orientações oficiais (BRASIL, 2010), observa-se certas inconsistências no processo inicial do ensino da leitura e da escrita. Por um lado, observamos práticas descontextualizadas e repetitivas, que ignoram os conhecimentos que as crianças já têm 
sobre a cultura e a linguagem escrita, desconsiderando-se as concepções atuais de ensino nesse campo, bem como a especificidade da Educação Infantil. São práticas assentadas em perspectivas preparatórias que ferem tanto as concepções de infância e de Educação Infantil, quanto as concepções contemporâneas de ensino e aprendizagem da língua escrita. Por outro lado, podemos observar, igualmente, práticas e discursos que negligenciam o contato das crianças pequenas com a escrita, sob o argumento de que esse é um aprendizado escolar, um saber reservado ao Ensino Fundamental, tendo a Educação Infantil o papel de resguardar o espaço do brincar.

Brandão e Leal (2011) referem-se a esses dois caminhos que a Educação Infantil tem tomado em relação à leitura e escrita como o caminho da "obrigação da alfabetização" - que seria o adiantamento das práticas alfabetizadoras do Ensino Fundamental - e o que definem como o caminho do "letramento sem letras", assim referido por Soares $(2004)^{2}$. Ao caminho do adiantamento, as autoras atribuem o trabalho descontextualizado com letras, iniciado pelas vogais, seguido pelas famílias silábicas e/ou pela associação entre fonemas e grafemas, a partir de práticas mecânicas questionadas mesmo para o ciclo de alfabetização, por abordar a notação escrita como um código de transcrição da fala. Há aí a valorização de que as crianças cheguem ao $1^{\circ}$ ano adiantadas no processo de decodificação da língua escrita.

Kleiman (2009) argumenta que outra perspectiva vê, por outro lado, o trabalho com a linguagem escrita nesse segmento como um "perigo educacional", como "escolarização" da Educação Infantil, "[...] devido à antecipação da introdução da criança ao ensino sistemático da língua escrita." (KLEIMAN, 2009, p.2). As crianças, supostamente, abandonariam prematuramente as brincadeiras e o espaço informal, devido à aprendizagem formal das salas de aula tradicionais. Essa visão apontada pela autora desdobra-se, no outro extremo, no que Brandão e Leal (2011) definem como o caminho do "letramento sem letras", ou seja, a perspectiva que enfatiza as diversas linguagens na Educação Infantil, e mesmo práticas letradas como a escuta de histórias, por exemplo, mas que se resguarda de abordar a notação da língua, por presumir que é um conteúdo escolar que não "combina" com as crianças pequenas. Nesse caso, essa não se constituiria como um objeto de aprendizagem nesse segmento, mantendo-se as crianças "assepticamente afastadas” do contato com a língua escrita (FERREIRO, 2001, p.38).

${ }^{2}$ Para um abordagem histórica mais ampla ver Brandão e Leal (2011) e Corsino (2011). 
Nesse modo de argumentar, há o pressuposto de que a escrita seria um conteúdo escolar distante e formal, que se aprende por ações necessariamente exaustivas e mecânicas, não adequadas aos pequenos e a seus modos de aprender. Brandão e Leal (2011) denunciam, inclusive, o preconceito desse modo de conceber a escola, enquanto Arce e Jacomeli (2012) questionam essa dissociação entre Educação Infantil e educação escolar, defendendo a abordagem da escrita nesse segmento, como prática sociocultural que é.

Kleiman (2009) aponta três falácias por trás dessa perspectiva, ancorada na ideia de que o processo de alfabetização só começaria na sala de aula do $1^{\circ}$ ano do Ensino Fundamental. A primeira é a de que o letramento seria um modelo de alfabetização, um letramento escolar, ou seja, relacionado ao ensino sistemático da escrita alfabética. A língua escrita é aí também reduzida ao sistema de notação. A segunda falácia diz respeito à ideia de que a criança vive em um mundo sem escrita, que esta lhe é opaca, invisível. Cria-se aí um absurdo: justamente a instituição responsável pelo ensino, a escola, limita a presença da escrita que circula amplamente no mundo social. A terceira falácia seria a de que a aprendizagem da linguagem escrita não pode ser lúdica - que brincar e aprender são inconciliáveis - o que vai de encontro a uma perspectiva do brincar como cultura da infância e como o modo peculiar de aprender dos sujeitos infantis. Conforme ressalta Baptista $(2010$, p.2): “[...] a brincadeira, forma privilegiada de a criança se manifestar e produzir cultura, é o elemento central para a constituição da ação educacional e deve ser entendida como fonte de conhecimento sobre a criança e sobre seu processo de apropriação e de produção de cultura".

Diante desse panorama de discussões, é preciso não apenas construir referenciais teóricos e práticos consistentes para pensar sobre o processo de apropriação da linguagem escrita na Educação infantil, mas enfrentar a questão e assegurar as conquistas teóricas e legais do campo. É preciso não perder tampouco de vista a importância fundamental da inserção das crianças na cultura e na linguagem escrita, desde a Educação Infantil, para os processos de letramento e de alfabetização. Se não houver clareza sobre o que é ler e escrever na Educação Infantil, corremos o risco de retomar práticas preparatórias exaustivas ou de deixar toda a responsabilidade de alfabetização e de letramento das crianças para os anos iniciais do Ensino Fundamental. A almejada alfabetização na idade certa terá muito mais chances de se concretizar nas escolas públicas, quando as experiências de letramento e de reflexão sobre a língua escrita na Educação Infantil forem produtivas, contextualizadas e significativas, 
possibilitando um acesso mais amplo das crianças à cultura escrita - desde que não se descuide, evidentemente, no Ensino Fundamental, dos avanços também necessários às práticas desse segmento, para que a responsabilidade não recaia na Educação Infantil.

A Educação Infantil tem um papel importante a assumir na formação de leitores e de usuários competentes da linguagem escrita, entendendo esses aspectos como produção de cultura e defendendo o direito das crianças à cultura letrada. Abordar a leitura e a escrita, nesse segmento, não significa, então, apresentar exercícios linguísticos preparatórios, descontextualizados, mas oportunizar a participação das crianças em diversas situações de leitura e produção de textos, em práticas letradas, para que, interagindo por meio da escrita, brincando de ler e escrever, em eventos de letramento diversos (MAYRINK-SABINSON, 1998; ARAUJO, 2012), convivendo com diversos materiais escritos, possam dizer por escrito, apropriar-se de comportamentos e procedimentos leitores, aprender sobre os usos e funções da escrita, refletir sobre seu funcionamento. É nesse sentido que Brandão e Leal (2011) apresentam, então, um terceiro caminho, que não é nem o de adiantamento, nem de negligência do ensino da linguagem escrita na Educação Infantil, mas o de "ler e escrever com significado”. Como discute Solé (apud BRANDÃO; LEAL, 2011) trata-se de tornar disponível o que já o está no meio sociocultural, e tornar "natural” e contínuo o ensino e a aprendizagem de algo que faz parte da vida das crianças e que não faz sentido algum ignorar.

Se a linguagem escrita diz respeito às crianças e lhes interessa, se elas aspiram aos conhecimentos que dizem respeito a sua cultura, a questão é, então, refletir sobre como apresentar a linguagem escrita respeitando a cultura da infância, os modos próprios de as crianças aprenderem, propondo, de forma sistemática, planejada e intencional, situações nas quais a leitura e escrita tenham sentido para elas, se fazendo presentes como interação e interlocução, prática discursiva, espaço de enunciação e de troca, espaço de dizer (CORSINO, 2011). Smolka (2000, p.45) afirma, a esse propósito, que não se trata apenas de ensinar a escrita, "[...] mas de usar, fazer funcionar a escrita como interação e interlocução na sala de aula, experienciando a linguagem nas suas várias possibilidades". Estamos aí muito longe da perspectiva de treinamentos linguísticos descontextualizados e da apresentação de uma versão escolar da leitura e escrita.

É importante sublinhar, no entanto, que as crianças não só se interessam pelos usos da escrita, suas funções sociais, mas querem saber também sobre o seu 
funcionamento. No contexto dos usos da linguagem escrita, as crianças indagam sobre os seus signos e o seu funcionamento, fazendo hipóteses e avançando em suas construções e aproximações sucessivas em relação ao sistema de notação - instrumento cultural importante para ampliar a participação na cultura letrada. Como afirma Baptista (2010, p.3), “[...] o desejo de compreender o sistema de escrita e dele se apropriar é fruto da interação da criança com a cultura escrita”. E como argumenta Ferreiro (2001), não é possível pensar sobre um objeto ausente. Não podemos perder de vista que os processos de letramento e de alfabetização são articulados, indissociáveis, embora possamos focar um ou outro no âmbito dos procedimentos didáticos.

Desse modo, Brandão e Leal (2011) englobam, dentre as "situações significativas de leitura e escrita" na Educação Infantil, não apenas os aspectos relacionados ao letramento, mas também aqueles relacionados à reflexão sobre a notação alfabética e a dimensão sonora da língua, articuladas às práticas letradas e/ou lúdicas da infância. Trata-se da faceta linguística, importante aspecto a ser abordado, ao lado da faceta sociodiscursiva (SOARES, 2004, 2016), e que não implica, necessariamente, em situações mecânicas e pouco significativas.

Ferreiro (2001), que denuncia também as posições de adiantamento ou de adiamento da escrita, lembra que a notação alfabética é fonte de curiosidade, de explorações, de indagações e de reflexão, também para as crianças pequenas. Aliás, do ponto de vista da aprendizagem, não é nem obrigatório nem proibitivo que, porventura, as crianças alcancem a alfabetização inicial na Educação Infantil - as crianças não pedem licença para aprender, é o que insiste a autora. Ao invertermos a questão de se devemos ou não ensinar a língua escrita na Educação Infantil, como sugere Ferreiro (2001), pensando não do ponto de vista do ensino, mas da aprendizagem, seria absurdo indagar se devemos permitir que a criança aprenda sobre a língua escrita. A aprendizagem é um processo contínuo, o sistema de ensino é que separa os segmentos há continuidade e não ruptura entre Educação Infantil e Ensino Fundamental, do ponto de vista da aprendizagem.

Desse modo, mesmo a pergunta sobre alfabetizar ou não na Educação Infantil, referindo-se aí ao processo de apropriação da notação da escrita, é uma pergunta falaciosa, pois seria necessário precisar o que se entende por "alfabetizar". A alfabetização pode ser referida como uma etapa específica da escolarização, que prevê a aprendizagem sistemática do funcionamento alfabético do sistema e, nesse caso, um processo que cabe ao ciclo de alfabetização, mas, por outro lado, pode ser vista como o 
processo contínuo de aprendizagem da notação da língua, que se inicia, como mostraram Ferreiro e Teberosky (1985), desde que as crianças começam a ter curiosidade e a formular hipóteses sobre a natureza e o funcionamento do sistema de escrita. Em outra perspectiva, considerando o que Vygotsky (1991) e Luria et al. (1988) chamaram de "pré-história da escrita", começa ainda antes, desde o desenvolvimento da função simbólica. A principal condição necessária para que uma criança seja capaz de compreender o funcionamento da escrita é que descubra que o que está em jogo é um sistema de signos que não têm significados em si mesmos. Como afirma Luria et al. (1988, p.143), “[...] a história da escrita na criança começa muito antes da primeira vez em que o professor coloca um lápis na sua mão e lhe mostra como formar as letras". Assim, nesse sentido de apropriação gradual, a alfabetização se configura como um processo contínuo que se inicia bem antes do Ensino Fundamental.

O construtivismo nos ensinou que a criança pensa - e ela pensa sobre tudo! Elas exploram inteligentemente o mundo da linguagem, dos textos, das palavras, dos sons da língua. Trata-se de cognição, não de percepção. Além do percurso de construção da escrita - seja este visto pelo viés psicogenético descrito por Ferreiro e Teberosky (1985), seja por um viés discursivo e sociointeracionista - as crianças também são extremamente sensíveis à dimensão sonora da língua falada, se encantando e experimentando jogos de linguagem com rimas, onomatopeias, aliterações e outras sonoridades. Um dos objetivos da Educação Infantil, no eixo linguístico, é que as crianças - a partir de seus esforços e descobertas, diante dos desafios postos pelo professor - prestem atenção aos significantes sonoros das palavras e se deem conta da relação da escrita com a pauta sonora da língua. Essa relação, quando estabelecida, inicialmente se apresenta como uma relação mais global, não termo a termo, mas a fonetização da escrita é um passo fundamental para a alfabetização acontecer.

Desse modo, prestar a atenção à dimensão sonora da língua é, como discutiremos a seguir, fundamental para a aprendizagem da escrita, junto às explorações de sua notação, e pode se constituir em um caminho produtivo - no contexto mais amplo das práticas letradas - de contribuição da Educação Infantil para os processos de alfabetização. Embora sejam inúmeras as situações em que as crianças estão aprendendo sobre a linguagem escrita antes dos 6 anos, é essa a questão que buscamos aqui discutir e enfatizar. 


\section{Brincar com a linguagem, as palavras, as sonoridades}

"Tem sílaba que leve oscila e cai como uma luva na canção".

(TATIT, 2000).

As crianças interessam-se pelas rimas, aliterações e outras particularidades da língua oral que vão observando no uso da linguagem e nas brincadeiras com as palavras faladas. Como afirma Oliveira (2012, p.213): “[...] além da função comunicativa, a língua oferece às crianças experiências nas quais brincar com as palavras é a função prioritária". Ademais, brincar com palavras e suas sonoridades também é uma prática sociocultural, que podemos observar nas interações entre e com as crianças, desde bem pequenas, seja em jogos orais, seja através de textos poético-musicais como acalantos, parlendas, trava-línguas, quadrinhas, cantigas. Os textos da tradição oral se apresentam como uma herança riquíssima da cultura popular para a exploração lúdica da linguagem. Presentes na Educação Infantil como cultura lúdica e como prática de oralidade são, como define Oliveira (2012, p.215) “[...] uma ótima oportunidade de imersão da criança na expressividade da sua língua". Além disso, faz parte da natureza desses gêneros a relação com a brincadeira - a brincadeira em geral e a brincadeira com a linguagem.

Além desse valor como cultura lúdica e como prática de oralidade, esses gêneros orais se relacionam também com o letramento, na perspectiva das inter-relações entre oralidade e escrita, ou seja, na medida em que as práticas orais se articulam às práticas letradas em diversos níveis, conforme discutem diversos autores, a exemplo de Rojo (1995) e Kleiman (1995). Para esta última, “[...] um olhar que veja a linguagem oral e a escrita não pelas diferenças formais, mas pelas semelhanças constitutivas, permite que pensemos a aquisição da escrita como um processo que dá continuidade ao desenvolvimento linguístico da criança”. (KLEIMAN, 1995, p.30). Os gêneros da tradição oral constituem-se, igualmente, como textos privilegiados para a alfabetização, pois chamam a atenção às sonoridades da língua e favorecem o estabelecimento de relações entre a oralidade e a escrita - aspectos importantes para a apropriação gradual do sistema de notação. E tudo isso articulado às experiências lúdicas que esse repertório pode proporcionar. A própria materialidade sonora da língua, musical e imagética, antes de ser escrita, já traz, em si mesma, a condição lúdica que permite que as explorações orais da linguagem, sobretudo no contexto da poesia oral e literária, mas também em diversos jogos orais ${ }^{3}$, se apresentem como brincadeiras. Cantar e recitar, identificar e

${ }^{3}$ Como a língua do pê, o telefone sem fio de rimas, o jogo "Lá vai a barca carregadinha de [...]". 
produzir rimas em parlendas e cantigas, tropeçar na pronúncia e observar os pequenos "sons" que se repetem em um trava-língua, segmentar as palavras em "pedaços" mínimos da emissão sonora no contexto da recitação, são aspectos que permitem explorações em contextos de brincadeiras com a linguagem, com esses gêneros poéticomusicais. Embora a unidade fonológica que se relaciona diretamente com a notação alfabética seja o fonema - que é muito abstrato para as crianças não alfabetizadas e se aprende no próprio curso da apropriação da escrita - brincar com as unidades fonológicas mais globais, como a rima e a sílaba ${ }^{4}$, leva a prestarem atenção à dimensão sonora da língua e, portanto, contribuirá, conforme indicado por diversos autores, com o processo gradual de apropriação do funcionamento sistema de escrita (BELINTANE, 2013; MORAIS; SILVA, 2011; SOARES, 2016; GOMBERT, 2013). As crianças são sensíveis às onomatopeias, aos paralelismos, às repetições, ao ritmo e às sonoridades em geral, presentes nesses textos da cultura oral. A sensibilidade às rimas nas cantigas, quadrinhas e parlendas, as escansões e segmentações silábicas nas brincadeiras cantadas e recitadas, a sensibilidade às aliterações em trava-línguas, são aspectos importantes para o desenvolvimento posterior da atividade metafonológica - a chamada consciência fonológica. Soma-se às brincadeiras com as sonoridades, o caráter frequentemente nonsense desses gêneros (que chama a atenção para o som, não para o sentido), favorecendo, igualmente, a atenção à dimensão fonológica de modo imbricado à ludicidade dos textos.

Gontijo (2014), entretanto, apresenta uma visão negativa e crítica do uso de textos da tradição oral na alfabetização, pelo fato de não tomar esses textos em sua dimensão cultural, como gêneros cujas funções são, justamente, brincar e brincar com a linguagem, tomando-os apenas pela perspectiva de uso como pretexto para o estudo mecânico das unidades mínimas da língua. Ela critica o fato de serem escolhidos devido à necessidade de se trabalhar os aspectos fonológicos e as relações fonema-grafema nas palavras que os compõem. Não é essa a visão que temos do trabalho com esses textos, pelo contrário, vemos essa abordagem no âmbito de uma concepção de sujeitos infantis como produtores de cultura e de história, tal qual defende a autora, que mobilizam, se apropriam e transformam os textos da cultura oral, herança cultural de nosso povo, brincando com a linguagem. E se não são os únicos textos que circulam socialmente - o

\footnotetext{
${ }^{4}$ Trata-se aqui da rima como elemento poético, rima da palavra, rhyme, não de rima da sílaba, parte da estrutura sonora da sílaba, rime - que é também uma unidade fonológica abordada nos estudos de consciência fonológica.
} 
letramento depende também do convívio com muitos outros gêneros - são privilegiados para abordar a faceta linguística da alfabetização, também fundamental, ao lado da faceta sociodiscursiva do letramento (SOARES, 2004, 2016). Ou seja, se os textos da tradição oral são privilegiados para aprender a ler e escrever, o são também porque, ao mesmo tempo, podem proporcionar situações reais e significativas de leitura, escrita e reflexão linguística, no contexto de práticas lúdicas. Não podemos nos esquecer que muito da matéria da poesia - suas sonoridades - é também matéria da alfabetização. Refletir sobre rimas ou sobre unidades fonológicas que se repetem nos trava-línguas pode tanto contribuir para prestar atenção na dimensão sonora da língua, quanto para conhecer mais sobre a linguagem poética e sobre esse gênero da poesia oral. Ou seja, as aprendizagens linguísticas e discursivas se dão, nesse caso, no bojo mesmo das funções poética e lúdica próprias aos gêneros da poesia oral, nos quais se evidencia a aproximação entre o espírito lúdico e os elementos poéticos. Desse modo, sua exploração linguística, pedagógica, deve resguardar essa natureza lúdica e estética. Brincando, ampliando o repertório de textos que se sabe de memória, e refletindo sobre as sonoridades em situações lúdicas, muitos aspectos linguísticos da aprendizagem da escrita podem ser favorecidos na Educação Infantil.

De qualquer modo, a ressalva de Gontijo (2014) é importante na medida em que precisamos estar atentos às práticas que negligenciam a perspectiva cultural e lúdica, de fato usando esses textos como meros substitutos dos textos cartilhados, esvaziando-os, inclusive, de sua potência performática - pela via da voz e da memória, como nos ensina Zumthor (1997) - ao apresentá-los já em sua forma escrita, sem assegurar a exploração oral e brincante própria a esses gêneros - o "ludismo gratuito dos versos", como ressaltam Aguiar e Ceccantini (2012, p.8). Apesar de privilegiados para a alfabetização, esses textos são, antes de mais nada, objetos de brincadeiras da cultura oral e jogos orais de linguagem, não escritos. Como gêneros orais, têm seus usos relacionados a essa característica e, portanto, mergulhar nesses textos, numa perspectiva de letramento, significa relacionar-se com eles tal qual circulam na cultura. Embora sejam hoje registrados em CDs e livros, circulando pela escuta mediatizada e pela leitura ou escuta da leitura, são textos que, originalmente, circulavam via oralidade, 
transmitidos pela memória de geração em geração - e suas características formais e natureza anônima têm relação com essa origem ${ }^{5}$.

$\mathrm{Na}$ poética da oralidade proposta por Zumthor (1997), em que a poesia se transmite pela voz e pela memória, o autor discute sobre os efeitos da presença, do ambiente e do corpo em ação, pela via do conceito de performance, esta vista como uma ação complexa pela qual uma mensagem poética é, no aqui e agora, simultaneamente transmitida e percebida. Para esse autor, por sua natureza, a poesia aspira sempre a se fazer ouvir - sua plenitude depende dessa vocalidade. Assim, não podemos perder de vista a dimensão de cultura oral desses gêneros poéticos, seu valor como texto que se sabe de memória, de cor, "de coração", e que se transmite oralmente, com todo o valor encantatório e performático da voz. Esse aspecto precisa ser compreendido para que a natureza lúdica e poética desses gêneros não seja perdida nas litanias escolares, que teimam em tomar os textos como meros pretextos para outra coisa que não fruir os textos. Ao contrário, abordar seus elementos poéticos-linguísticos pode, inclusive, ampliar a fruição dos textos, e não "matá-los". Assim, é essencial explorá-los, primordialmente e inicialmente, via oralidade, como gêneros orais que são, antes de qualquer abordagem por escrito, até para ser coerente com seus usos, funções e características, em termos de letramento.

Dito isto, ressalta-se, no entanto, que uma vez memorizados para constituir um repertório de brincadeiras, os textos da tradição oral são privilegiados também para o reconhecimento de palavras, a reflexão sobre a notação escrita e a relação entre a escrita e a pauta sonora da língua. Como afirma Oliveira (2012, p.215) “[...] ao memorizar esses textos que se precisa saber de cor para brincar, as crianças ganham um repertório para as primeiras experiências de leitura". Acompanhar a leitura de um texto memorizado, estabelecendo relação entre a escrita e a língua falada, bem como identificar palavras ou parte de palavras, com apoio do ritmo dos versos, das repetições e das rimas, são situações produtivas de leitura quando ainda não se lê convencionalmente. Não se trata aí de defender a leitura ideovisual ou a adivinhação aleatória, trata-se de pesquisa inteligente, de usar pistas textuais e todo o conhecimento disponível, inclusive sobre relações entre escrita e pauta sonora, entre grafia e unidades fonológicas, colocando tudo o que se sabe em jogo (ARAUJO, 2011).

${ }^{5}$ Ao ler, em vez de recitá-los de cor, perde-se muitas marcas dessa origem oral. Além disso, Zumthor (1997) chama a atenção para o fato de que a perfomance mediatizada pelas tecnologias também não tem as mesmas características da performance oral presentificada. 
Além dos aspectos já apontados, podemos buscar em Belintane (2013) outros argumentos em defesa dos textos da tradição oral na alfabetização. Questionando o excesso de pragmatismo e utilitarismo do uso de textos cotidianos funcionais no letramento das crianças, o autor propõe que se tome a função poética e a oralidade como pontos de partida, defendendo que o letramento "[...] comporta o oral e, essencialmente, os gêneros que privilegiam a função poética”. (BELINTANE, 2013, p.121). Ressaltando o relevo que os gêneros de origem oral têm no imaginário infantil, ele afirma: “[...] insisto que esse estofo linguageiro é fundamental para uma alfabetização dinâmica porque constitui as matrizes textuais que estabilizam e fornecem o fluxo, o ritmo, a dicção, dando corpo a uma leitura significativa e de maior envergadura". (BELINTANE, 2013, p.121). É importante sublinhar, no entanto, que, embora proponha diversos jogos de linguagem com a estrutura fonológica da língua, o autor considera o enredamento discursivo entre a língua na infância e os textos da cultura com tendo uma dimensão inconsciente, questionando tomá-los do ponto de vista das operações de consciência.

É possível, no entanto, relativizar a questão do uso do termo "consciência" (awareness) nessa expressão, a partir da conceituação da reflexão de natureza fonológica como atividade metalinguística - esta tomada como atividade metacognitiva, como capacidade de se distanciar do uso comunicativo da linguagem para prestar atenção a suas propriedades linguísticas (GOMBERT, 1990, 2013) ${ }^{6}$. Os próprios estudos sobre as atividades metafonológicas, como de qualquer outro tipo de atividade metalinguística, preveem uma sensibilidade implícita, epilinguística, que não resulta de um controle consciente por parte de quem realiza os procedimentos linguísticos ${ }^{7}$. Nos seus estudos mais recentes, o autor afirma que "[...] a criança começa a adquirir implicitamente conhecimentos sobre as características estruturais da escrita a partir do momentos em que presta atenção a ela de forma repetida, bem antes do início das aprendizagens escolares". (GOMBERT, 2013, p.113). Dentre essas características, o autor engloba também a dimensão fonológica. Assim, admite que há aprendizagens implícitas ocorrendo na Educação Infantil, sejam sobre a escrita, sejam sobre sua estrutura fonológica, que se reelaborarão depois em termos metalinguísticos e, em

\footnotetext{
${ }^{6}$ Alguns autores têm sugerido também o uso de outros termos para traduzir phonological awareness, tais que análise fonológica ou sensibilidade fonológica (SOARES, 2016; MORAIS apud MORAIS, 2015).

${ }^{7}$ Para o estabelecimento da relação entre fonema e grafema, há a necessidade de um maior controle e consciência dessas operações sobre a linguagem. Gombert (2013), no entanto, revê a questão, enfatizando o papel das atividades epilinguísticas na apropriação da escrita.
} 
alguns casos, seguirão intervindo ainda de forma implícita ${ }^{8}$. Desse modo, as crianças caminham, gradativamente, de um brincar espontâneo, de uma detecção ou produção global das sonoridades (CORREA, 2001), para uma competência analítica, metafonológica. Assim, os textos poético-musicais da tradição oral e suas brincadeiras com as sonoridades - rimas, sílabas, unidades maiores e menores que a sílaba, fonemas em aliteração - favorecem o caminho que vai da sensibilidade epilingística à competência analítica, metafonológica, necessária à alfabetização - quando a observação de semelhanças sonoras entre rimas e entre sílabas iniciais, bem como a observação de aliterações e fonemas, já pode adquirir um caráter mais explícito ${ }^{9}$.

No caso das crianças pequenas, apenas brincando de pular corda, com recitação de textos que acompanham essa brincadeira, ou brincando de "Lá vai a bola", de "Chicotinho queimado", há uma tendência a segmentar oralmente as palavras, o que vai favorecer, posteriormente, a alfabetização, pois essa escansão das sílabas chama a atenção aos segmentos sonoros que constituem as palavras. Como ressalta Belintane (2013, p.133), o que se escande aí é, geralmente, algo maior que a sílaba, mas, mesmo assim, constitui “[...] um bom caminho na busca de uma língua escandível, alfabetizável”, afinal, brincar com diversos níveis de segmentação das palavras favorece a atenção à dimensão sonora da língua. Mesmo os fonemas consonantais - que são unidades abstratas difíceis de isolar na corrente da fala e de perceber na oralidade, sem apoio na escrita - podem ser observados quando ouvidos repetidamente nas aliterações de um trava-língua. Como ressalta Araujo (2011), diferentemente dos fonemas oclusivos, os fricativos e vibrantes são mais fáceis de se detectar oralmente, mas mesmo os oclusivos, em aliteração (como aparecem nos trava-línguas), se tornam observáveis na sua repetição ${ }^{10}$. Repetição brincante.

De todo modo, ao contrário do que argumenta Gontijo (2014), ressalta-se a importância desses gêneros no letramento e na alfabetização, tomados nessa dimensão cultural e performática, como cultura lúdica infantil, com tudo o que ela tem de potente e produtiva como repertório de textos que circulam socialmente e que se ofertam às brincadeiras com a língua, no seus próprios modos de constituir práticas de linguagem. Longe de uma perspectiva de treinamento fonológico e fonêmico, trata-se aqui de

\footnotetext{
8 A perspectiva de Belintane (2013), no entanto, é psicanalítica e, nesse campo, o conceito de inconsciente difere da perspectiva das operações implícitas, inconscientes, nos estudos de psicologia cognitiva da leitura.

${ }^{9}$ Conceito de aliteração aqui tomado no âmbito da poética, como repetição de fonemas consonantais.

${ }^{10}$ Ressalta-se, mais uma vez, que se não trata de percepção, mas de cognição, metacognição.
} 
refletir sobre essa dimensão linguística, no âmbito de apropriações culturais e de uma concepção de criança que pensa - e pensa inclusive sobre os aspectos fonológicos da língua.

\section{Considerações finais}

Defender a brincadeira com linguagem para favorecer a apropriação da escrita supõe uma concepção de ensino que considera as aprendizagens relativas à faceta linguística, ao lado da faceta sociodiscursiva. Diversos autores e centros de pesquisa de universidades brasileiras (BRANDÃO; LEAL, 2011; SOARES, 2004, 2016; VÓVIO, 2016) vêm discutindo a necessidade de, na prática pedagógica, contemplar e articular essas diversas facetas - muitas vezes estudadas por diferentes campos de conhecimento. Defendem, no entanto, que os aspectos linguísticos sejam abordados não a partir de concepções mecanicistas e empiristas da escrita como código de transcrição da fala, mas a partir do reconhecimento da escrita como prática sociodiscursiva e sistema complexo de notação - sistema que é necessário aprender para participar mais amplamente das práticas letradas.

A partir do que foi discutido, podemos argumentar que a reflexão sobre a dimensão sonora da língua e de suas relações com o sistema de escrita podem se dar na Educação Infantil sem ferir o princípio das experiências significativas, lúdicas e prazerosas com a linguagem, podendo, pelo contrário, ser mobilizada, justamente, em situações lúdicas com textos e palavras. Além da poesia de tradição oral, também os jogos fonológicos orais ou de mesa e as brincadeiras com os nomes próprios são igualmente possíveis e produtivos na Educação Infantil, que vêm cumprir essa função pedagógica sem perder de vista a função lúdica, necessária para se constituírem, de fato, como jogos e brincadeiras, conforme ressalta Kishimoto (2003).

O direito à alfabetização e ao letramento é parte do direito à educação. A Educação Infantil é a etapa inicial do processo de escolarização em que os primeiros contatos com a cultura escrita podem e devem se dar de modo específico a essa faixa etária, em consonância com os princípios e modos de aprender das crianças pequenas, mas sem descuido das diversas aprendizagens que precisam ser favorecidas e ampliadas, de forma contínua e integrada, e que incluem, a linguagem escrita, em suas várias dimensões. Conceber o trabalho pedagógico em uma dimensão cultural é o caminho 
mais contundente para se pensar na abordagem da escrita na educação das crianças, desde o início de sua inserção no sistema educacional.

\section{REFERÊNCIAS}

AGUIAR, V. T.; CECCANTINI, J. L. (Org.). Poesia infantil e juvenil brasileira. 1.ed. São Paulo: Cultura Acadêmica, 2012.

ARAUJO, L. Quem os desmafagafizar bom desmafagafizador será: textos da tradição oral na alfabetização. Salvador: Edufba, 2011. Disponível em: <http://www.slideshare.net/Licaraujo/textos-da-tradio-oral-na-alfabetizao>. Acesso em: 9 dez. 2016.

ARAUJO, L. Tá iquito aqui! Eventos de letramento e as práticas de leitura e escrita antes da alfabetização. In: ARAPIRACA, M. A.; BELTRÃO, L. M. F.; SILVA, C. S. (Org.). Estudos e passagens do Proinfantil na Bahia. 1.ed. Salvador: EDUFBA, 2012. p.49-64. Disponível em: <file:///C:/Users/ss1011639/Downloads/estudos-e-passagensdo-proinfantil-na\%20Bahia.pdf>. Acesso em: 9 dez. 2016.

ARCE, A.; JACOMELI, M. R. M. (Org.). Educação infantil versus educação escolar? Entre a (des)escolarização e a precarização do trabalho pedagógico nas salas de aula. 1.ed. Campinas: Autores Associados, 2012.

BAKHTIN, M.; VOLOCHINOV, V. N. Marxismo e filosofia da Linguagem. 1.ed. São Paulo: HUCITEC, 1981.

BAPTISTA, M. C. A linguagem escrita e o direito à educação na primeira infância. Brasília: Ministério da Educação, 2010.

BELINTANE, C. Oralidade e alfabetização: uma nova abordagem da alfabetização e do letramento. 1.ed. São Paulo: Cortez, 2013.

BRANDÃO, A. C. P.; LEAL, T. F. Alfabetizar e letrar na educação infantil: o que isso significa? In: BRANDAO, A. C. P.; ROSA, E. C. S. Ler e escrever na educação infantil: discutindo praticas pedagógicas. Belo Horizonte: Autêntica, 2011. p.13-31.

BRASIL. Ministério da Educação. Secretaria de Educação Básica. Diretrizes Curriculares Nacionais para a Educação Infantil. Brasília: MEC/SEB, 2010.

BRASIL. Ministério da Educação. Emenda constitucional no 59 de 11 de novembro de 2009. Acrescenta $\S 3^{\circ}$ ao art. 76 do Ato das Disposições Constitucionais Transitórias para reduzir, anualmente, a partir do exercício de 2009, o percentual da Desvinculação das Receitas da União incidente sobre os recursos destinados à manutenção e desenvolvimento do ensino de que trata o art. 212 da Constituição Federal, dá nova redação aos incisos I e VII do art. 208, de forma a prever a obrigatoriedade do ensino de quatro a dezessete anos e ampliar a abrangência dos programas suplementares para 
todas as etapas da educação básica, e dá nova redação ao $\S 4^{\circ}$ do art. 211 e ao $\S 3^{\circ}$ do art. 212 e ao caput do art. 214, com a inserção neste dispositivo de inciso VI. Diário Oficial da União, Brasília, 12 nov. 2009.

BRASIL. Ministério da Educação. Plano Nacional de Educação 2014-2024: Lei $n^{\circ}$ 13.005, de 25 de junho de 2014, que aprova o Plano Nacional de Educação (PNE) e dá outras providências. Brasília: Câmara dos Deputados, Edições Câmara, 2014. (Série Legislação, 125).

BRESCIANE, A. L. Alfabetização e educação infantil: relações delicadas. Revista Avisa Lá, São Paulo, n.17, p.37-39, jan. 2004.

COHN, C. Antropologia da criança. 1.ed. Rio de Janeiro: Jorge Zahar Ed., 2005. (Coleção Passo-a-passo, 57).

CORREA, J. A aquisição do sistema de escrita por crianças. In: CORREA, J.; SPINILLO, A.; LEITÃO, S. (Org.). Desenvolvimento da linguagem: escrita e textualidade. 1.ed. Rio de Janeiro: Nau Editora: FAPERJ, 2001. p.19-70.

CORSINO, P. Professoras de educação infantil e suas visões de letramento: tensões da prática. In: ROCHA, E. A. C.; KRAMER, S. Educação infantil: enfoques em diálogo. 3.ed. Campinas: Papirus, 2011. p.241-257 (Série Prática Pedagógica).

FERREIRO, E. Com todas as letras. 9.ed. São Paulo: Cortez, 2001.

FERREIRO, E.; TEBEROSKY, A. Psicogênese da língua escrita. 1.ed. Porte Alegre: Artes Médicas, 1985.

GOMBERT, J. E. Epi/meta versus implícito/explícito: nível de controle sobre a leitura e sua aprendizagem. In: MALUF, M. R.; CARDOSO-MARTINS, C. (Org.). Alfabetização no século XXI: como se aprende a ler e escrever. Porto Alegre: Penso, 2013. p.109-123.

GOMBERT, J. Le Développement métalinguistique. 1.ed. Paris: PUF, 1990.

GONTIJO, C. M. M. Alfabetização: políticas mundiais e movimentos nacionais. 1.ed. Campinas: Autores Associados, 2014.

KISHIMOTO, T. O jogo e a educação infantil. In: KISHIMOTO, T. (Org.). Jogo, brinquedo, brincadeira e a educação. 7.ed. Cortez. São Paulo, 2003. p.13-43.

KLEIMAN, A. Projetos de letramento na educação infantil. Caminhos em Linguística Aplicada, Taubaté, v.1, n.1, p.1-10, 2009.

KLEIMAN, A. Os significados do letramento: uma nova perspectiva sobre a prática social da escrita. 1.ed. Campinas: Mercado de Letras, 1995.

LURIA, A. R. et al. Linguagem, desenvolvimento e aprendizagem. 4.ed. São Paulo: Ícone/EDUSP, 1988. p.143-189. 
MAYRINK-SABINSON, M. L. T. Reflexões sobre o processo de aquisição da escrita. In: ROJO, R. (Org.). Alfabetização e letramento: perspectivas linguísticas. 1.ed. Campinas: Mercado de Letras, 1998. p.123-159.

MORAIS, A. G. O desenvolvimento da consciência fonológica e a apropriação da escrita alfabética entre crianças brasileiras. Revista Brasileira de Alfabetização ABAlf, Vitória, v.1, n.1, p.59-76, jan./jun. 2015.

MORAIS, A. G.; SILVA, A. Consciência fonológica na educação infantil: desenvolvimento de habilidades metalinguísticas e aprendizado da escrita alfabética. In: BRANDAO, A. C. P.; ROSA, E. C. S. Ler e escrever na educação infantil: discutindo praticas pedagógicas. 1.ed. Belo Horizonte: Autêntica, 2011. p.73-92.

OLIVEIRA, Z. R. O trabalho do professor na educação infantil. 1.ed. São Paulo: Editora Biruta, 2012.

ROJO, R. Concepções não valorizadas de escrita: a escrita como 'um outro modo de fala'. In: KLEIMAN, A. (Org.). Os significados do letramento: uma nova perspectiva sobre a prática social da escrita. 1.ed. Campinas: Mercado de Letras, 1995. p.15-61.

SARMENTO, M. J. Imaginário e culturas da infância. Cadernos de Educação. Fae/UFPel, Pelotas, v.12, n.21, p.51-59, jul./dez. 2003.

SMOLKA, A. L. B. A criança na fase inicial da escrita: a alfabetização como processo discursivo. 9.ed. São Paulo: Cortez, 2000.

SOARES, M. Alfabetização: a questão dos métodos. 1.ed. São Paulo: Contexto, 2016.

SOARES, M. Letramento e alfabetização: as muitas facetas. Revista Brasileira de Educação, Rio de Janeiro, n.25, p.5-17, jan./abr. 2004.

TATIT, L. As sílabas. In: TATIT, L. O meio. São Paulo: Dabliú Discos, 2000. CDROM.

VÓVIO, C. L.; ROMERO, M. A formação de leitores no ciclo de alfabetização: a palavra escrita como brinquedo e a leitura como brincadeira. In: SILVEIRA, E. et al. (Org.). Alfabetização na perspectiva do letramento: letras e números nas práticas sociais. Florianópolis: UFSC/CED/NUP, 2016. p.153-175.

VYGOTSKY, L. S. A formação social da mente. 1.ed. São Paulo: Martins Fontes, 1991 .

ZUMTHOR, P. Introdução à poesia oral. 1.ed. São Paulo: Hucitec, 1997. 


\section{Como referenciar este artigo}

ARAUJO, Liane Castro de. Brincar com a linguagem: educação infantil "rima" com alfabetização? Revista Ibero-Americana de Estudos em Educação, Araraquara, v.11, n. esp. 4, p. 2325-2343, 2016. Disponível em: <http://dx.doi.org/10.21723/riaee.v11.n.esp4.9196>. E-ISSN: 1982-5587.

Submetido em: agosto/2016

Aprovado em: outubro/2016 